\title{
Optimal targeting of BCL-family proteins in head and neck squamous cell carcinoma requires inhibition of both BCL-xL and MCL-1
}

\author{
Thomas J. Ow ${ }^{1,2,12}$, Cory D. Fulcher ${ }^{1}$, Carlos Thomas ${ }^{2}$, Pilib Ó Broin ${ }^{3}$, Andrea López ${ }^{4}$, \\ Denis E. Reyna ${ }^{4}$, Richard V. Smith ${ }^{1,2,5,12}$, Catherine Sarta ${ }^{1}$, Michael B. Prystowsky ${ }^{2,12}$, \\ Nicolas F. Schlecht ${ }^{2,6,7,8}$, Bradley A. Schiff ${ }^{1}$, Gregory Rosenblatt ${ }^{2}$, Thomas J. Belbin ${ }^{2,9}$, \\ Thomas M. Harris², Geoffrey C. Childs ${ }^{2}$, Nicole Kawachi ${ }^{2}$, Chandan Guha ${ }^{2,10,12}$ and \\ Evripidis Gavathiotis ${ }^{4,11,12}$

\footnotetext{
${ }^{1}$ Department of Otorhinolaryngology-Head and Neck Surgery, Montefiore Medical Center/Albert Einstein College of Medicine, Bronx, NY, USA

${ }^{2}$ Department of Pathology, Montefiore Medical Center/Albert Einstein College of Medicine, Bronx, NY, USA

${ }^{3}$ School of Mathematics, Statistics, and Applied Mathematics, National University of Ireland Galway, Galway, Ireland

${ }^{4}$ Department of Biochemistry, Albert Einstein College of Medicine, Bronx, NY, USA

${ }^{5}$ Department of Surgery, Montefiore Medical Center/Albert Einstein College of Medicine, Bronx, NY, USA

${ }^{6}$ Department of Epidemiology \& Population Health, Montefiore Medical Center/Albert Einstein College of Medicine, Bronx, NY, USA

${ }^{7}$ Department of Medicine (Oncology), Montefiore Medical Center/Albert Einstein College of Medicine, Bronx, NY, USA

${ }^{8}$ Department of Cancer Prevention \& Control, Roswell Park Comprehensive Cancer Center, Buffalo, NY, USA

${ }^{9}$ Discipline of Oncology, Memorial University of Newfoundland, St. John's, NL, Canada

${ }^{10}$ Department of Radiation Oncology, Montefiore Medical Center/Albert Einstein College of Medicine, Bronx, NY, USA

${ }^{11}$ Department of Medicine (Cardiology), Montefiore Medical Center/Albert Einstein College of Medicine, Bronx, NY, USA

${ }^{12}$ Albert Einstein Cancer Center, Bronx, NY, USA
}

Correspondence to: Thomas J. OW, email: thow@montefiore.org

Keywords: head and neck squamous carcinoma; MCL-1; BCL-xL; navitoclax; A-1210477

Received: April 24, $2018 \quad$ Accepted: December 16, $2018 \quad$ Published: January 11, 2019

Copyright: Ow et al. This is an open-access article distributed under the terms of the Creative Commons Attribution License 3.0 (CC BY 3.0), which permits unrestricted use, distribution, and reproduction in any medium, provided the original author and source are credited.

\section{ABSTRACT}

Mechanisms of treatment resistance in head and neck squamous cell carcinoma (HNSCC) are not well characterized. In this study, HNSCC tumors from a cohort of prospectively enrolled subjects on an ongoing tissue banking study were divided into those that persisted or recurred locoregionally $(n=23)$ and those that responded without recurrence $(n=35)$. Gene expression was evaluated using llumina HumanHT12-v3 Expression BeadChip microarrays. Sparse Partial Least Squares - Discriminant Analysis (sPLS-DA) identified 135 genes discriminating treatment-resistant from treatment-sensitive tumors. BCL-xL was identified among $23 \%$ of canonical pathways derived from this set of genes using Ingenuity Pathway analysis. The BCL-xL protein was expressed in 8 HNSCC cell lines examined. Cells were treated with the BCL-xL inhibitor, ABT-263 (navitoclax): the average half maximal inhibitory concentration

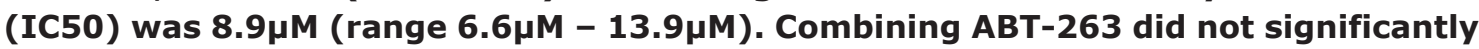
increase responses to 2 Gy radiation or cisplatin in the majority of cell lines. MCL1 , a potential mediator of resistance to ABT-263, was expressed in all cell lines and HNSCC patient tumors, in addition to BCL-XL. Treatment with the MCL-1 inhibitor, A-1210477, in HNSCC cell lines showed an average IC50 of $10.7 \mu \mathrm{M}$ (range, $8.8 \mu \mathrm{M}$ to 12.7 $\mu \mathrm{M}$ ). Adding A-1210477 to ABT-263 (navitoclax) treatment resulted in an average 


\section{7-fold reduction in the required lethal dose of ABT-263 (navitoclax) when measured across all 8 cell lines. Synergistic activity was confirmed in PCI15B, Detroit 562, MDA686LN, and HN30 based on Bliss Independence analysis. This study demonstrates that targeting both BCL-xL and MCL-1 is required to optimally inhibit BCL-family pro- survival molecules in HNSCC, and co-inhibition is synergistic in HNSCC cancer cells.}

\section{INTRODUCTION}

Head and neck squamous cell carcinoma (HNSCC) is diagnosed in approximately 55,000 patients in the United States each year [1], and it is among the most common cancers worldwide [2]. HNSCC arises at sites in the upper aerodigestive tract, including the oral cavity, larynx, and pharynx. Treatment recommendations for patients with HNSCC are selected based on disease site, clinical stage, and the morbidity associated with different treatment options. Approximately $50 \%$ of patients with HNSCC present with American Joint Committee on Cancer (AJCC) stage III or IV disease [3-5], and the vast majority of these patients receive radiation or combination cisplatin-radiation as either first-line or adjuvant therapy $[6,7]$. For the last two decades there has been a consistent locoregional failure rate of $20-30 \%$ that has shown little if any improvement over that time $[6,8]$. Thus, one can surmise that many locoregional recurrences of HNSCC represent either re-growth of tumor cells that have survived cisplatin and/or radiation treatment or new malignant cells that have arisen within the treated field. To date, little is known about the molecular factors that contribute most significantly to treatment failure in HNSCC.

Evasion of apoptosis is a 'hallmark of cancer' [9]. Oncogenic stressors (eg. DNA damage, unchecked cell proliferation) are known to elicit the activation of apoptosis signaling, which serves as a defense against the process of tumorigenesis. Additionally, radiation and cytotoxic chemotherapy cause preferential tumor cell death via accumulation of fatal DNA damage, which can lead to apoptosis as one potential mechanism of tumor cell death. Thus, disruption of apoptosis signaling plays a key role in the development of cancer, cancer cell survival, and resistance to therapy.

The process of apoptosis is controlled by a balance among several initiators, mediators, and inhibitors. The BCL2 family proteins work in concert to regulate the initiation of the intrinsic apoptosis pathway. Pro-survival BCL-2 proteins, such as BCL-2, BCL-xL, and MCL-1, inhibit BCL-2 pro-apoptotic effectors, such as BAX and BAK. The pro-apoptotic effectors promote apoptosis by forming pore complexes in the mitochondrial membrane leading to release of oxygen free-radicals and cytochrome $\mathrm{c}$, which in turn activate the caspase cascade leading to programmed cell death [10]. Upregulation of pro-survival BCL-2 proteins is a known mechanism by which cancer cells disrupt apoptosis signaling [11]. This mechanism has been previously reported in HNSCC [12, 13], and upregulation of BCL-2 has been shown to be associated with cisplatin resistance and poor outcome in oropharyngeal squamous cell carcinoma [14, 15]. There have been limited studies examining BCL-xL and MCL-1 in HNSCC. Because anti-apoptotic proteins such as BCL-2, BCL-xL, and MCL-1 work in concert to inhibit apoptosis, the redundant role that these molecules play in HNSCC deserves further examination.

In the current study, we compare HNSCC tumors that were eradicated by chemoradiation to those that persisted or recurred locoregionally after treatment. Gene expression data were analyzed to identify transcripts that could differentiate these two groups, and BCL-xL was noted to be involved in several key networks among the genes identified. This led us to examine the efficacy of small-molecule targeting of BCL$x L$ in HNSCC. Treatment with ABT-263 (navitoclax), a small molecule inhibitor of BCL-2/BCL-xL, was effective in killing HNSCC cells at high doses, but had limited additive effect in combination with radiation or cisplatin. This led to examination of factors limiting the efficacy of BCL-xL/ BCL-2 inhibition, specifically MCL-1 activity. MCL-1 expression was associated with resistance to radiation in HNSCC cells and found to increase in expression after treatment with ABT-263 (navitoclax). Co-inhibition of MCL-1 was required to optimize approaches targeting BCL2/BCL-xL in HNSCC, resulting in synergistic activity.

\section{RESULTS}

\section{Gene expression profile comparing treatment failures to responders}

A cohort of patients with HNSCC were selected for the study based on the inclusion and exclusion criteria described in the methods section. The characteristics of the patient cohort are presented in Table 1. Patients with HNSCC who received radiation as a component of therapy and failed treatment $(\mathrm{n}=23$, with median time to failure $=15$ months) were compared to patients who were treated with radiation or chemoradiation and remained free of locoregional recurrence at last follow-up $(\mathrm{n}=35$, median follow-up 41 months). For one subject in the failure group, gene expression data from both the primary tumor and the recurrent tumor were included in the analysis, as gene expression data was captured for both tumors. A comparison between characteristics for the failure group and the responder group, including primary tumor site, p16-assessment among oropharynx cancer patients, stage at diagnosis, and presence of lymph node disease, are presented in Table 1. Only disease primary site showed a statistically significant difference between groups, with a 
Table 1: Patient and tumor characteristics

\begin{tabular}{|c|c|c|c|c|c|}
\hline \multirow[t]{2}{*}{ Variables } & \multicolumn{2}{|c|}{ Failure Group } & \multicolumn{2}{|c|}{ Responder Group } & \multirow[t]{2}{*}{ p-value } \\
\hline & $\mathbf{N}$ & $\%$ & $\mathbf{N}$ & $\%$ & \\
\hline Total & 23 & 100 & 35 & 100 & \\
\hline \multicolumn{6}{|l|}{ Site } \\
\hline Larynx & 7 & $30 \%$ & 18 & $51 \%$ & 0.03 \\
\hline Oropharynx & 9 & $39 \%$ & 15 & $43 \%$ & \\
\hline p16+ & 4 & $17 \%$ & 6 & $17 \%$ & \\
\hline p16- & 4 & $17 \%$ & 7 & $20 \%$ & \\
\hline unknown & 1 & $4 \%$ & 2 & $6 \%$ & \\
\hline Oral Cavity & 7 & $30 \%$ & 2 & $6 \%$ & \\
\hline \multicolumn{6}{|l|}{ Stage } \\
\hline I, II & 2 & $9 \%$ & 2 & $6 \%$ & 0.66 \\
\hline III, IV & 21 & $91 \%$ & 33 & $94 \%$ & \\
\hline \multicolumn{6}{|l|}{ Nodal Status } \\
\hline Positive & 18 & $78 \%$ & 29 & $83 \%$ & 0.66 \\
\hline Negative & 5 & $22 \%$ & 6 & $17 \%$ & \\
\hline
\end{tabular}

larger proportion of patients with oral cavity disease in the disease failure group (chi-square, $\mathrm{p}=0.03$ ).

The gene expression profiles of tumors from patients with locoregional failure were compared to the profiles of tumors from responders using sPLS-DA (Figure 1B). The optimal sPLS-DA model had 100 features selected on each of two components, so nominally, 200 probesets (Supplementary Figure 1 - crossvalidation plot). Once duplicates and control probes were removed, 170 remained. Predicted genes/ pseudogenes were removed, and 135 genes were ultimately identified that could be used to differentiate the two groups (Supplementary Table 1). A heatmap of the selected genes demonstrating segregation of the responder group and failure group is presented in Figure 1C. The identified genes were analyzed using IPA analysis. 73 canonical pathways were identified, and notably, BCL-xL was involved in 17 (23\%) of these pathways. Based on this observation, BCL-family prosurvival molecules were selected for further study. The top pathways identified with IPA and networks involving BCL$\mathrm{xL}$ are summarized in Supplementary Table 2. Since BCL-xL was identified as a key transcript involved in pathways that differentiated treatment-resistant from treatment-sensitive tumors, we proceeded to examine the role of BCL-xL and related family members in response to standard treatment and as potential treatment targets.

\section{Radiation and cisplatin response profiles of HNSCC cell lines}

Eight HNSCC cell lines (HN30, HN31, PCI15A, PCI15B, UMSCC6, MDA686LN, HN5, and Detroit562) were used to examine responses to radiation and cisplatin. Surviving fraction of cells after exposure to $2 \mathrm{~Gy}, 4 \mathrm{~Gy}$, and $6 \mathrm{~Gy}$ radiation were examined in clonogenic survival assays performed in triplicate. HNSCC cell lines demonstrated a range of survival to $2 \mathrm{~Gy}$ radiation - from HN30: $55.1 \%$ $( \pm 10.7 \%$ Standard Error (SEM)) to Detroit562: $89.2 \% \quad( \pm 4.6 \% \quad \mathrm{SEM})$. Data for more radiation sensitive cell lines (HN30, PCI15A, UMSCC6, and MDA686LN) are presented in Figure 2A, and more radiation resistant lines $(\mathrm{HN} 31, \mathrm{HN} 5, \mathrm{PCI} 15 \mathrm{~B}$, and Detroit562) in Figure 2B. The cell lines were ranked by relative radiation sensitivity based on responses to $2 \mathrm{~Gy}$ radiation (Figure 2C). Data for Figure 2A, 2B, and $2 \mathrm{C}$ are also included in tabular form in Table 2. For the remainder of this paper where cell lines are listed, they remain in the order of relative radiation sensitivity (based on surviving fraction at $2 \mathrm{~Gy}$ ) for ease of reference.

Cell viability assays using MTT (3-(4,5-dimethylthiazol-2-yl)-2,5-diphenyltetrazolium bromide) were also used to assess response of the 8 cell lines to cisplatin treatment. The half maximal inhibitory concentration (IC50) for cisplatin ranged from PCI15A: $2.81 \mu \mathrm{M}$ (standard deviation (SD) \pm 0.99$) \mu \mathrm{M}$ to UMSCC6: $13.29 \mu \mathrm{M}$ (SD $\pm 0.88 \mu \mathrm{M})$. Representative cell viability curves are presented in Figure $2 \mathrm{D}-2 \mathrm{~K}$, and average IC50 values from assays done in triplicate are presented in Figure 2L. Cisplatin response showed no significant correlation with response to radiation among these 8 cell lines (Pearson's $r=-0.016, p=0.97$ ). 


\section{BCL-2 and BCL-xL expression and response to standard treatment and ABT-263}

In vitro studies were carried out to determine if $\mathrm{BCL}-\mathrm{xL}$, and related anti-apoptosis family members were associated with radiation and cisplatin response. The efficacy of targeting BCL-xL therapeutically was also examined. Baseline protein expression of BCL-2 and $\mathrm{BCL}-\mathrm{xL}$ were assessed using Western Blot. BCL-xL was strongly and consistently expressed in all cell lines, while
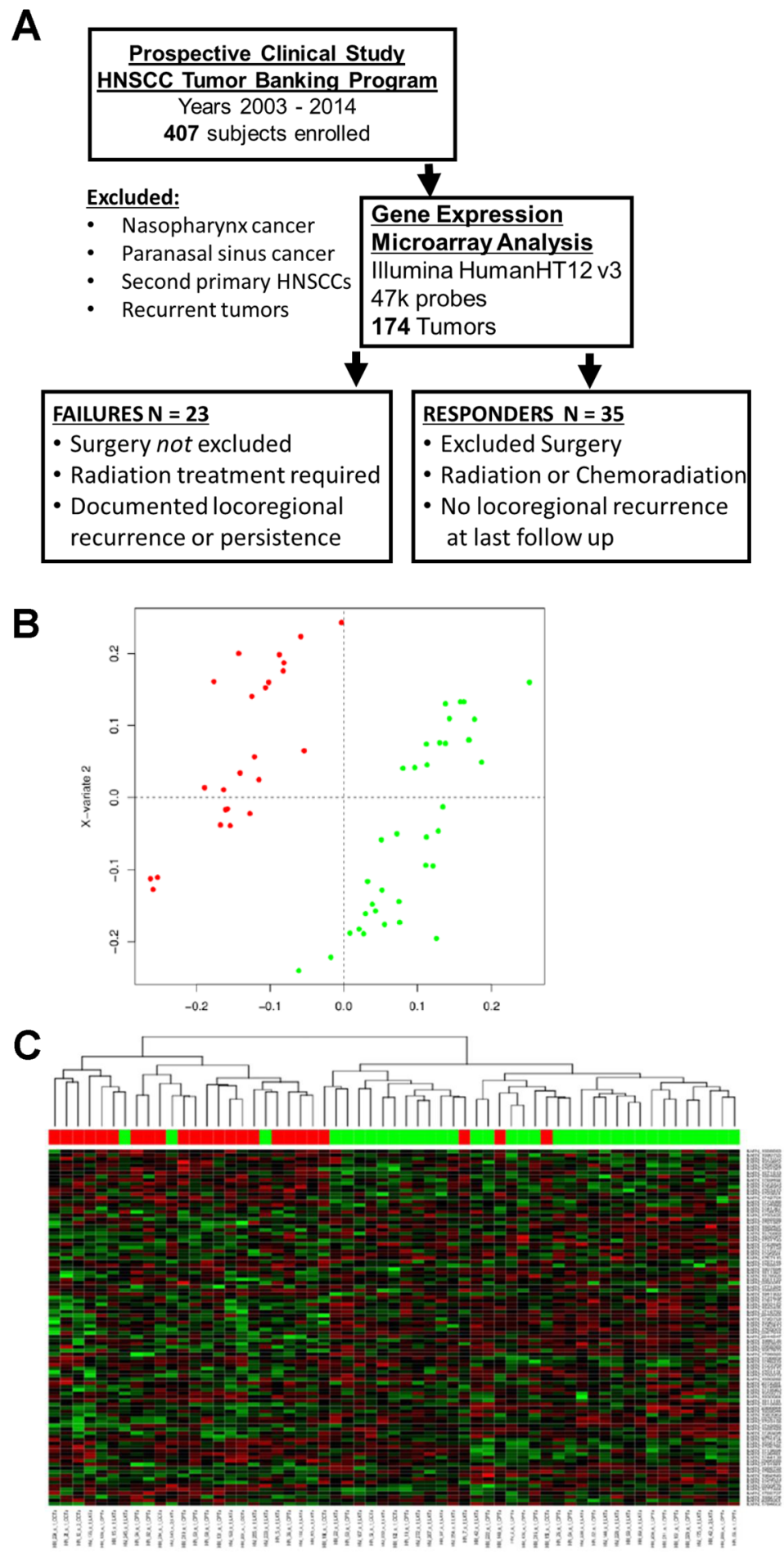

Figure 1: Patient cohort and gene expression data. (A) Diagram describing the selection process for patients deemed failures and responders used for gene expression analysis. (B) Diagram of results from sparse Partial Least Squares-Discriminant Analysis (sPLS-DA). Red - failure cases, green - responder cases. (C) Heatmap of gene expression profiles from genes selected on the first component of the sPLS-DA model shows HNSCC treatment responders largely cluster separately from failures. 
Table 2: Surviving fraction at $2 \mathrm{~Gy}, 4 \mathrm{~Gy}$, and $6 \mathrm{y}$ radiation based on clonogenic survival assays for head and neck squamous cell carcinoma cell lines

\begin{tabular}{lcccccc}
\hline Cell line & 2Gy (\%SF) & S.E.M. & 4Gy (\%SF) & S.E.M. & 6Gy (\%SF) & S.E.M. \\
\hline HN30 & 55.1 & \pm 15.16 & 35.5 & \pm 23.12 & 20.1 & \pm 17.47 \\
UMSCC6 & 59.1 & \pm 15.12 & 11.9 & \pm 7.80 & 0.8 & \pm 0.57 \\
PCI15A & 65.2 & \pm 2.31 & 23.3 & \pm 5.84 & 9.9 & \pm 6.36 \\
MDA686LN & 65.3 & \pm 1.40 & 32.4 & \pm 11.63 & 16.9 & \pm 2.10 \\
HN31 & 74.2 & \pm 6.75 & 38.0 & \pm 17.89 & 17.3 & \pm 13.72 \\
HN5 & 83.6 & \pm 6.62 & 44.0 & \pm 13.91 & 21.0 & \pm 6.92 \\
PCI15B & 87.4 & \pm 2.19 & 50.0 & \pm 13.91 & 24.5 & \pm 6.92 \\
DET562 & 89.2 & \pm 6.53 & 37.4 & \pm 5.51 & 22.4 & \pm 7.27 \\
\hline
\end{tabular}

Abbreviations: Gy (Gray); SF (surviving fraction); S.E.M. (standard error of the mean).

conversely, BCL-2 showed very weak or no expression in 7 cell lines: only HN5 demonstrated consistent high expression of BCL-2 (Figure 3A). There was no clear association between BCL-2 or BCL-xL basal expression and response to radiation or cisplatin.

ABT-263 (navitoclax) is a potent inhibitor of BCL$\mathrm{xL}$, with activity against BCL-2 and BCL-w [16]. The HNSCC cell line panel was treated with ABT-263 and responses were characterized via cell viability assays using MTT, tested in triplicate. Consistent responses to ABT-263 were noted in all cell lines tested at relatively high doses for each line (Figure 3B, Supplementary Figure 2). The IC50 to ABT-263 ranged from $4.77 \mu \mathrm{M} \pm 1.66 \mu \mathrm{M}$ (HN31) to $13.85 \mu \mathrm{M} \pm 1.95 \mu \mathrm{M}$ (MDA686LN), with an average overall IC50 of $8.9 \mu \mathrm{M}$. There was not a clear association noted between drug response in each line and
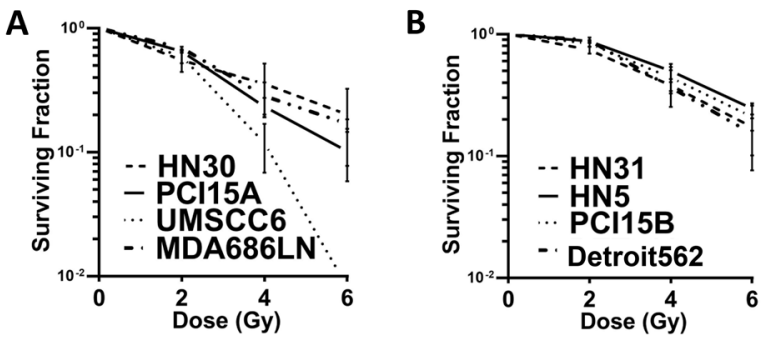

C
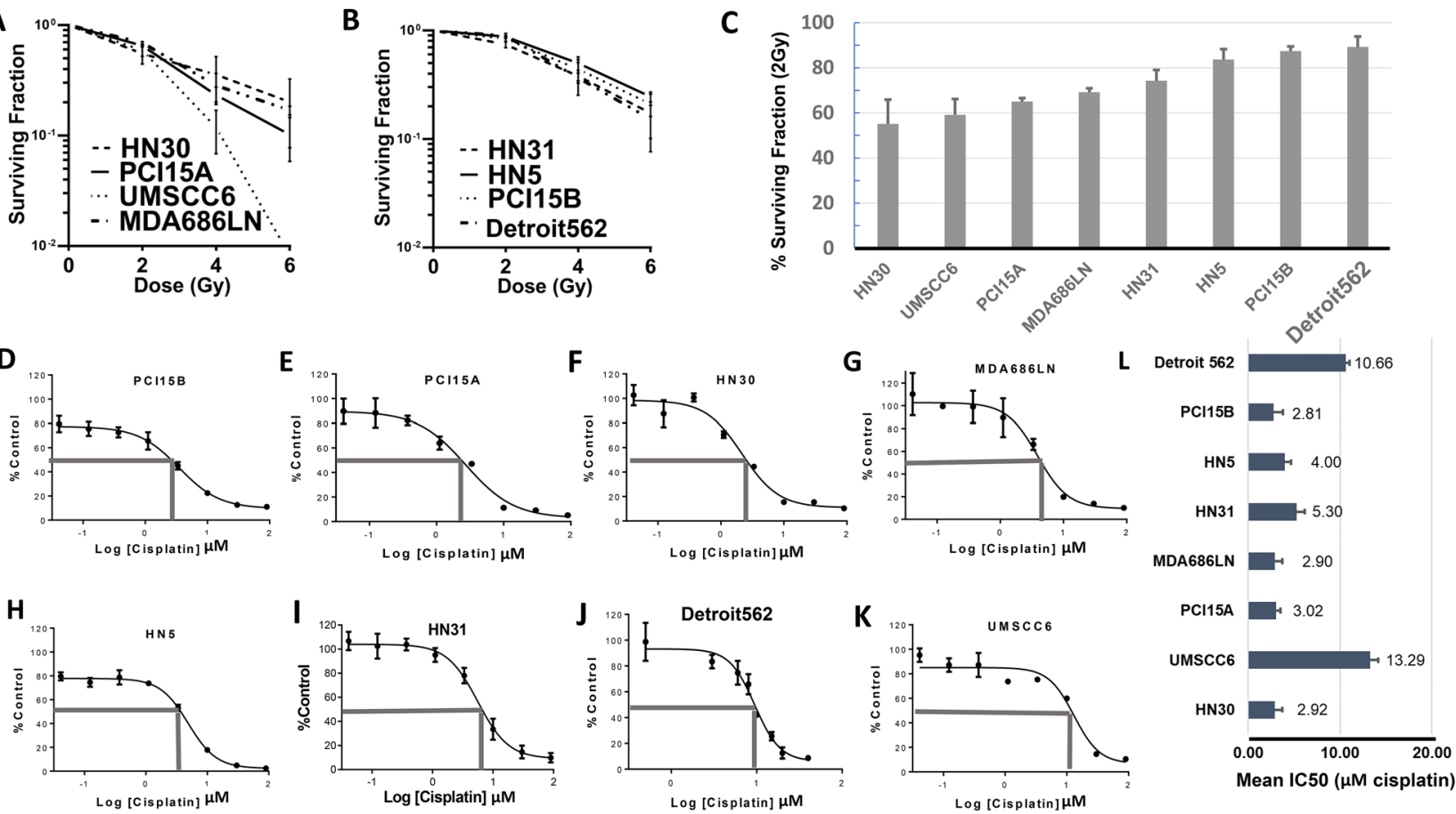

Mean IC50 ( $\mu \mathrm{M}$ cisplatin)

Figure 2: Baseline profiling of radiation and cisplatin response in HNSCC cell lines. Results from clonogenic survival assays showing radiation sensitive (A) and radiation resistant (B) head and neck squamous cell carcinoma cell lines - average surviving fraction with standard error of the mean (S.E.M., error bars) is calculated from triplicate experiments; (C) Graphical representation of surviving fraction after 2 Grey dose of radiation (SF 2Gy), with cell lines arranged from most sensitive to most resistant; (D-K) Representative results from MTT assays of cisplatin in head and neck squamous cell cancer cell lines organized from most sensitive (D-G) to most resistant (H-K) to cisplatin. (L) Graphical representation of the average IC50, with S.E.M. (error bars) (MTT assay done in triplicate), cell lines arranged according to radiation sensitivity. There was no significant correlation between radiation sensitivity and IC50 dose for cisplatin. 
baseline BCL-xL protein levels, radiation sensitivity, or cisplatin sensitivity.

The efficacy of ABT-263 in combination with 2Gy radiation was evaluated in clonogenic survival assays examining the panel of 8 HNSCC cell lines, performed in duplicate. A third trial was not performed because combination treatment was generally ineffective. $2 \mu \mathrm{M}$ and $4 \mu \mathrm{M}$ doses of ABT-263 were studied (Figure 3C). In general, ABT-263 (navitoclax) did not appear to radiosensitize $\mathrm{HNSCC}$ cells, and combining radiation with ABT-263 yielded only modest benefit in two lines (HN30, PCI15A).
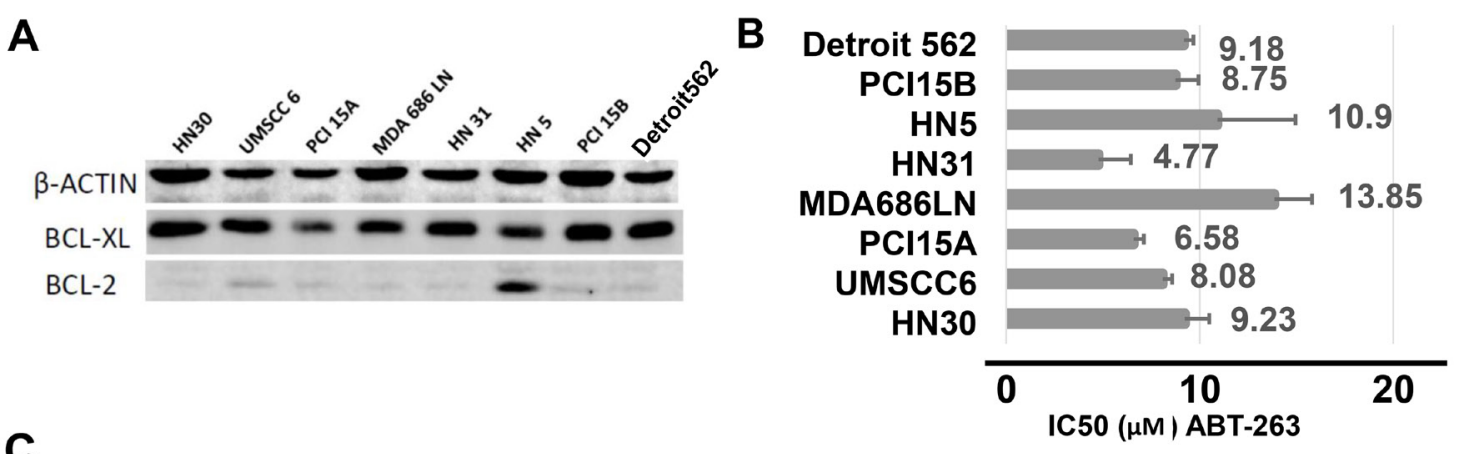

C

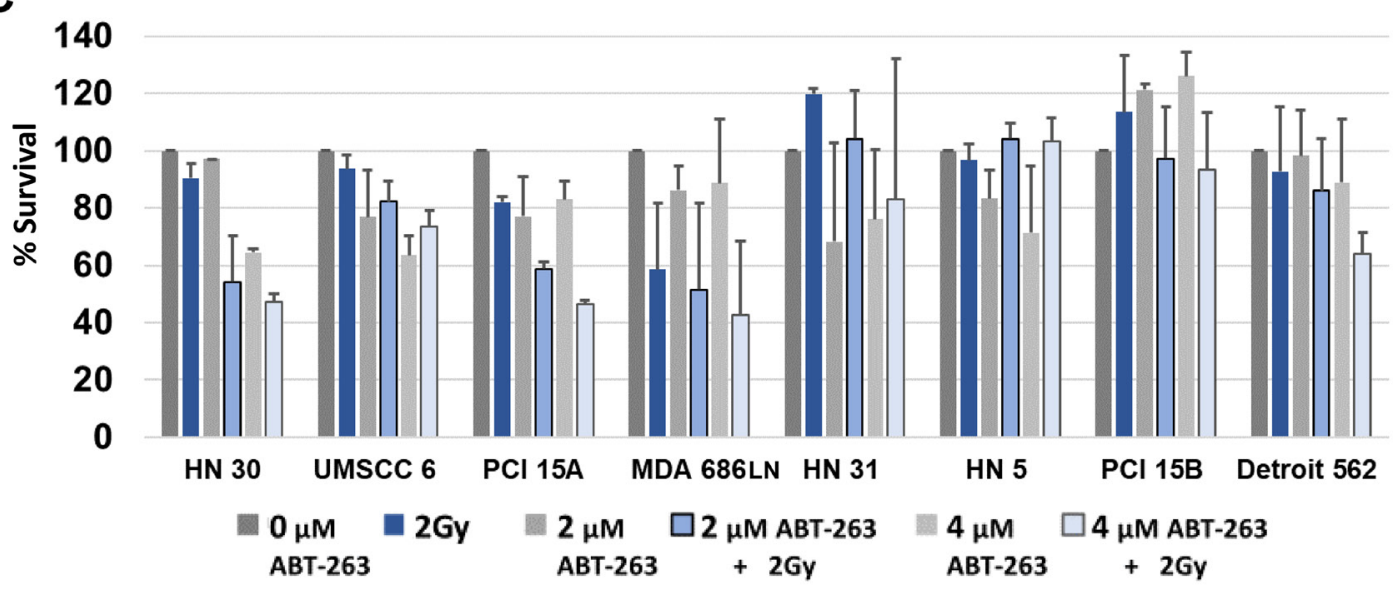

D

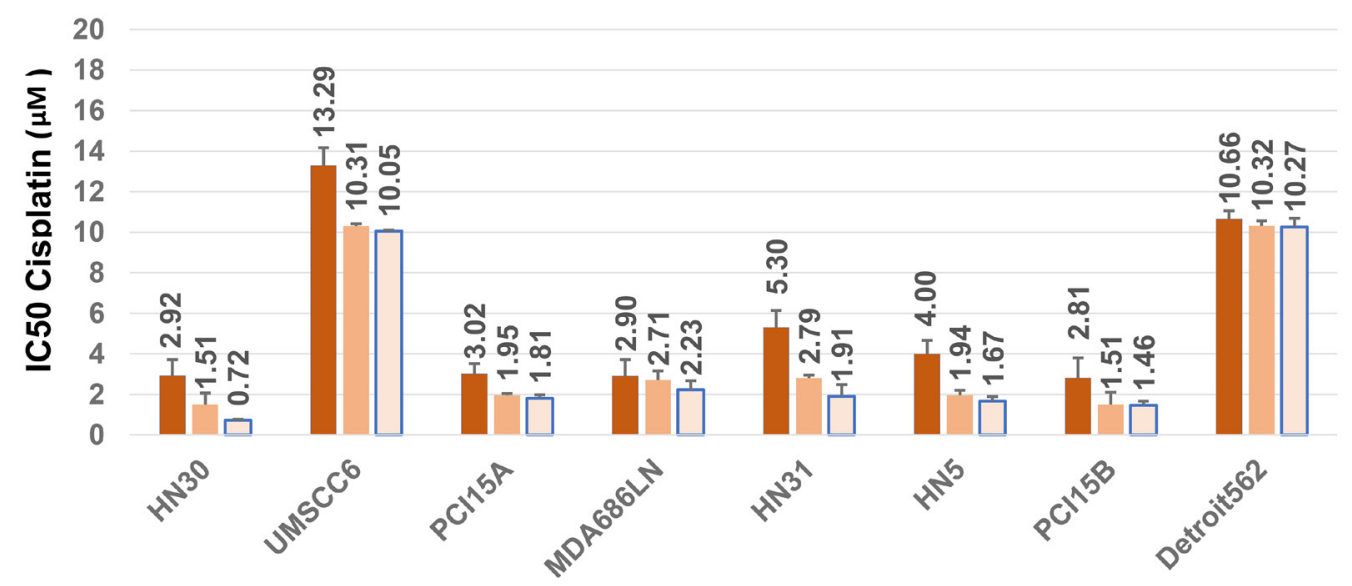

$0 \mu \mathrm{M}$

Figure 3: Baseline BCL-xL expression and inhibition of BCL-xL with ABT-263 (navitoclax) treatment of HNSCC cells, alone and in combination with radiation or cisplatin. (A) Western blot demonstrating consistent high expression of BCL-xL and rare expression of BCL-2 in HNSCC cells. (B) Average IC50 values, with S.E.M. (error bars), after treatment with ABT-263 (navitoclax) assessed from cell viability assays using MTT. (C) Percent Survival calculated from clonogenic survival assays, with S.E.M. (error bars), after treatment of HNSCC cells with $2 \mu \mathrm{M}$ or $4 \mu \mathrm{M}$ ABT-263 (navitoclax) alone or in combination with 2 Gy radiation. (D) Average IC50 values, with S.E.M. (error bars), for cisplatin given in combination with $2 \mu \mathrm{M}$ and $4 \mu \mathrm{M}$ ABT-263 (navitoclax). 
The effect of combining cisplatin with ABT-263 was also studied using cell viability assays with MTT. We examined whether $2 \mu \mathrm{M}$ and $4 \mu \mathrm{M}$ doses of ABT-263 reduced the IC50 of cisplatin when given in combination. ABT-263 did decrease the IC50 of cisplatin in most cell lines (Figure 3D), however improvements were generally modest. For example, HN30 showed an approximately 4-fold decrease in the cisplatin requirement to achieve the IC50 after treatment with $4 \mu \mathrm{M}$ of ABT-263 $(2.92 \mu \mathrm{M}$ $\pm 0.80 \mu \mathrm{M}$ vs. $0.72 \mu \mathrm{M} \pm 0.05 \mu \mathrm{M})$, while Detroit562 showed no change in the IC50 $(10.66 \mu \mathrm{M} \pm 0.40 \mu \mathrm{M}$ vs. $10.27 \mu \mathrm{M}$ $\pm 0.41 \mu \mathrm{M})$.

Overall, the effect of inhibition of BCL-xL/BCL2/BCL-w with ABT-263 in combination with standard therapy for HNSCC was not robust, which led to an exploration of possible mechanisms of resistance to ABT-263.

\section{MCL-1 expression in HNSCC cell lines and the HNSCC patient cohort}

ABT-263 targets BCL-xL and BCL-2, but does not target the MCL-1 protein, another BCL-2 family pro-survival molecule. We therefore examined MCL1 expression across the panel of 8 HNSCC cell lines using Western Blot (Figure 4A). Notably, the cell lines with highest MCL-1 expression were among those most resistant to radiation. In addition, we also examined expression of the BCL-2, BCL-xL, and MCL-1 transcript levels in the study patient cohort. The transcript expression levels in patient tumors mirrored protein expression observed in HNSCC cell lines - ie. expression of BCL2 was very low, while expression levels of BCL-xL and MCL-1 were comparably high (Figure 4B). The expression values were compared between the treatment "failure" and treatment "responsive" groups. The expression levels of BCL-xL and MCL-1 were both elevated in tumors that failed treatment compared to those that responded, however these differences did not reach a $\mathrm{p}<0.05$ threshold for significance. For BCL-xL, median expression among responders was 1579 (IQR 1304, 2030), compared to failures $(1900, \mathrm{IQR} 1454,2175)(\mathrm{p}=0.08)$. For MCL1 , responders was 1489 (IQR 1271, 1832), compared to failures $(1665$, IQR 1418, 1888) $(\mathrm{p}=0.23)$.

It was also hypothesized that treatment with ABT263 (navitoclax) would result in upregulation of MCL-
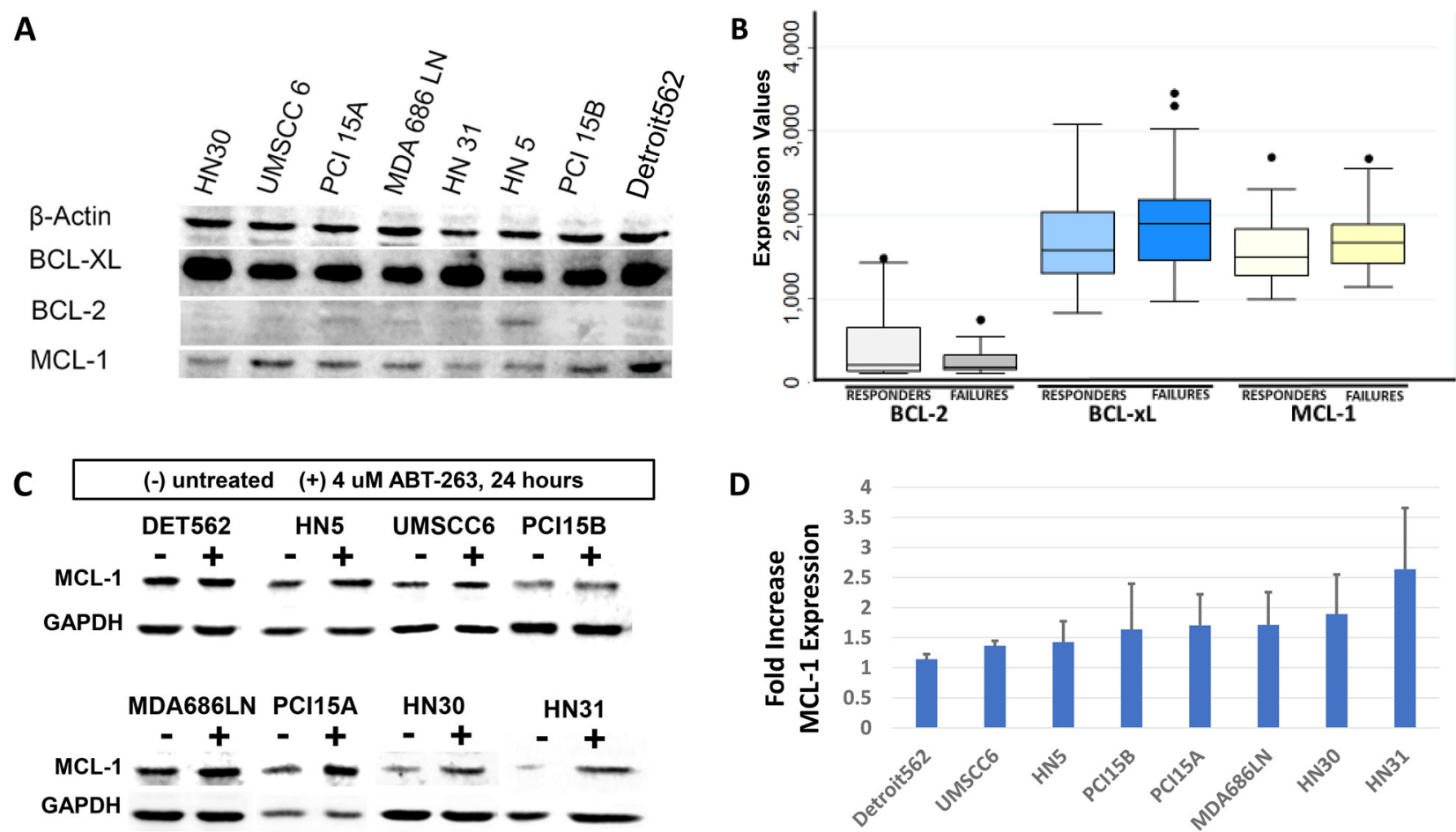

Figure 4: Evaluation of MCL-1 expression in HNSCC. (A) Western blot demonstrating baseline MCL-1 expression in HNSCC cell lines, compared to BCL-xL and BCL-2 expression as demonstrated previously. Cell lines most resistant to radiation (HN5, PCI15B, Detroit562) demonstrate high MCL-1 expression. (B) Box and whisker plot representing gene expression transcript levels for BCL-2, BCL-xL, and MCL-1 as measured on gene expression microarrays in the HNSCC patient cohort, stratified by "responders" and "failures". Lines represent median average transcript levels; Boxes represent $25^{\text {th }}$ and $75^{\text {th }}$ percentile, whiskers represent $2^{\text {nd }}$ and $98^{\text {th }}$ percentile. Dots represent outlying data points. (C) Western blot demonstrating MCL-1 protein expression at baseline, and 24 hours after treatment with $4 \mu \mathrm{M}$ ABT-263 (navitoclax). (D) Quantification of MCL-1 expression shows consistent increases of average MCL-1 expression, with standard deviation (error bars), after treatment with ABT-263 (navitoclax). 
1 expression. MCL-1 expression was evaluated in the panel of 8 cell lines 24 hours after treatment with $4 \mu \mathrm{M}$ of ABT-263. MCL-1 was indeed noted to increase in all cell lines after ABT-263 (navitoclax) treatment (Figure $4 \mathrm{C}$, Figure 4D). Paired $t$-test comparing MCL-1 levels between untreated and treated samples showed that MCL-1 was significantly increased after treatment with ABT-263 ( $p=0.04)$. BCL-2 and BCL-xL levels were also examined on western blot before and after treatment of 4 $\mu \mathrm{M}$ ABT-263. BCL-2 was not expressed in several lines, both before and after treatment, and no consistent increase in expression was observed. BCL-xL was significantly increased after treatment with ABT-263 $(\mathrm{p}=0.01)$.

\section{Effect of dual inhibition of BCL-xL and MCL-1}

In addition, we tested the response of the HNSCC cell lines to a recently-described [17] selective small molecule inhibitor against MCL-1: A-1210477 using MTT assays. Responses to this agent were consistent in all lines tested, with IC50 dosages ranging between $9.44 \pm 1.19 \mu \mathrm{M}$ (HN31) to $12.65 \mu \mathrm{M} \pm 0.84 \mu \mathrm{M}$ (Detroit 562) (Figure 5A, Supplementary Figure 3).

Next, the efficacy of A-1210477 was examined in combination with ABT-263 using MTT assays. HNSCC cell lines were treated with $2.5 \mu \mathrm{M}$ and $5 \mu \mathrm{M}$ doses of A-1210477 to determine if this resulted in a dose reduction required to achieve the IC50 with ABT-263. The assays were performed in triplicate. The IC50 of ABT-263 was substantially reduced in all cell lines tested (Figure 5B). The IC50 dose of ABT-263 was reduced on average 7-fold when combined with $5 \mu \mathrm{M}$ of A-1210477, ranging from 1.4-fold (HN5) to 22.3-fold (MDA686LN).

It was suspected that the drug combination of ABT263 and A-1210477 was synergistic based on results of the 8 cell line panel. Four of the cell lines (PCI15B, Detroit 562, MDA686LN, HN30) were examined using cell viability assays, with expanded dose ranges to allow for Bliss Independence synergy analysis. These were performed in duplicate as they were confirmatory to the MTT assays. Bliss Independence analysis showed there was synergy observed for the drug combination in each line (Figure 6). Results in PCI15B were modest with synergy noted when $10 \mu \mathrm{M}$ of A-1210477 was administered, however the other three lines demonstrated synergy when $2.5 \mu \mathrm{M}$ of A-1210477 was administered with ABT-263 (navitoclax).

\section{DISCUSSION}

It remains unclear why some HNSCC tumors respond exquisitely to cisplatin and radiation, while others fail. We used an analysis of gene expression data to differentiate between HNSCCs that recur or persist after treatment versus those that do not. Other studies have taken a similar approach. Ginos and colleagues [18] compared gene expression profiles from microarray data between 41 HNSCC samples and 13 normal controls to identify a signature that was specific to HNSCC tumor specimens, and they also used the expression data to identify genes that could differentiate HNSCCs that recurred versus those from patients who had not exhibited a recurrence. Of note, this study included several specimens that had been harvested after primary treatment and recurrence, while only 7 specimens in the recurrence group were from pre-treatment biopsies. Another study by Chung, et al. [19], examined 60 HNSCC samples using gene expression microarrays, and gene expression profiles for these tumors were segregated into four groups using unsupervised methods. When examining the association of
A

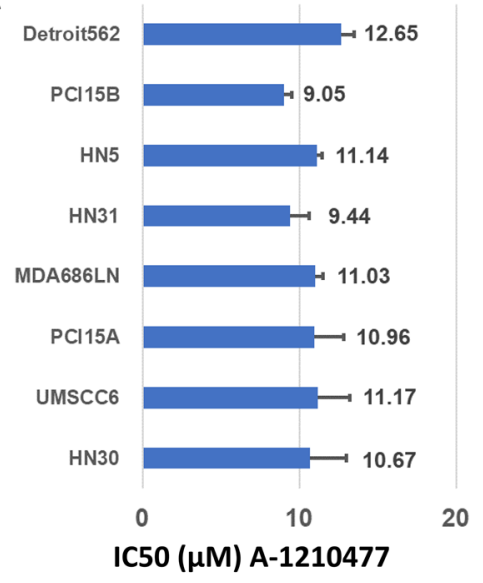

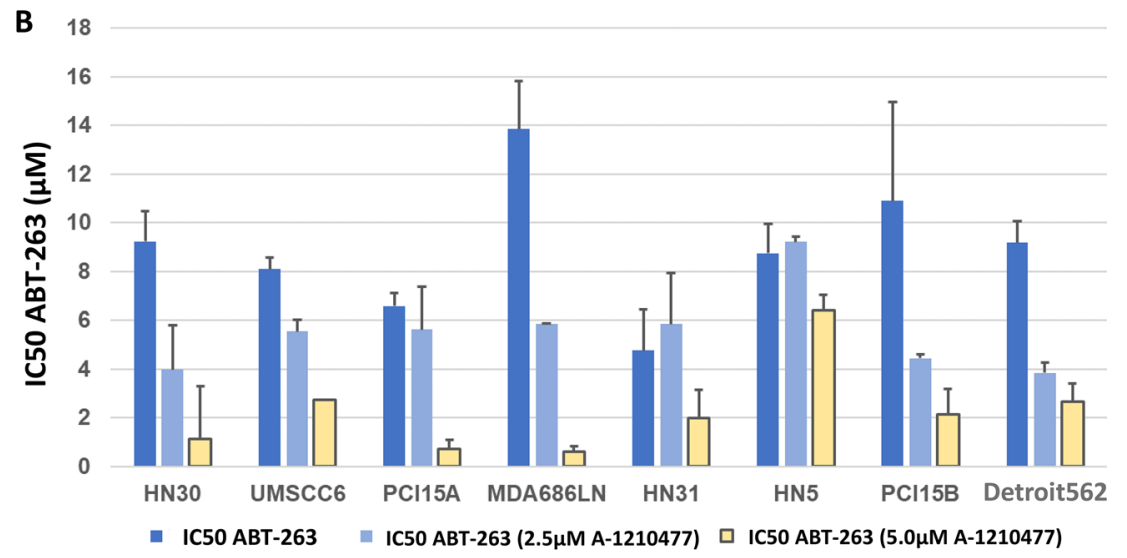

Figure 5: Inhibition of MCL-1 in HNSCC cells with A-1210477, alone and in combination with ABT-263 (navitoclax). (A) Average IC50 values, with S.E.M. (error bars), for A-1210477 in HNSCC cell lines. (B) Average IC50 values, with S.E.M. (error bars), for ABT-263 (navitoclax) in combination with $2.5 \mu \mathrm{M}$ and $5 \mu \mathrm{M}$ A-1210477. Note that baseline IC50 values for A-1210477 (A) vary slightly from control values (B) as these were carried out as independent experiments with triplicate data for each. 
A

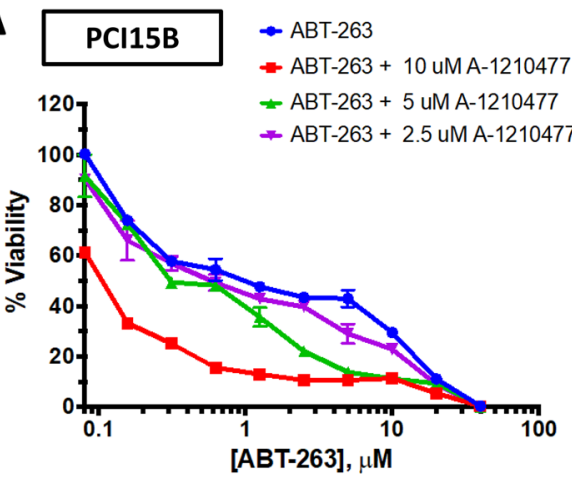

B
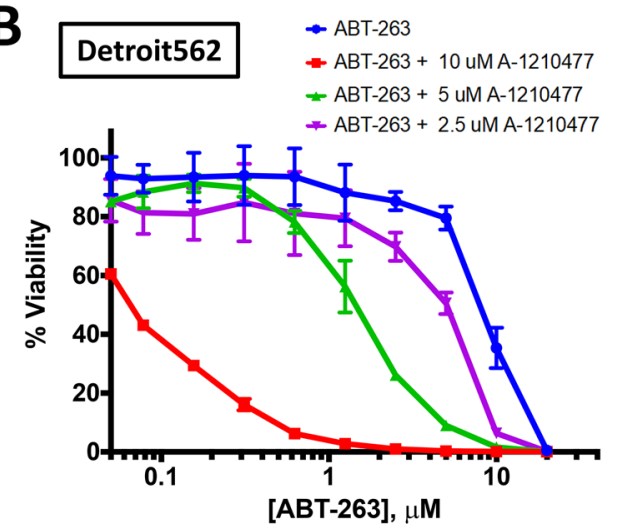

C
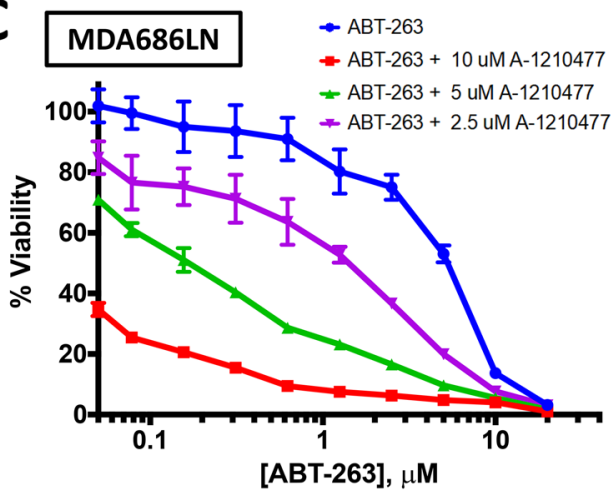

D

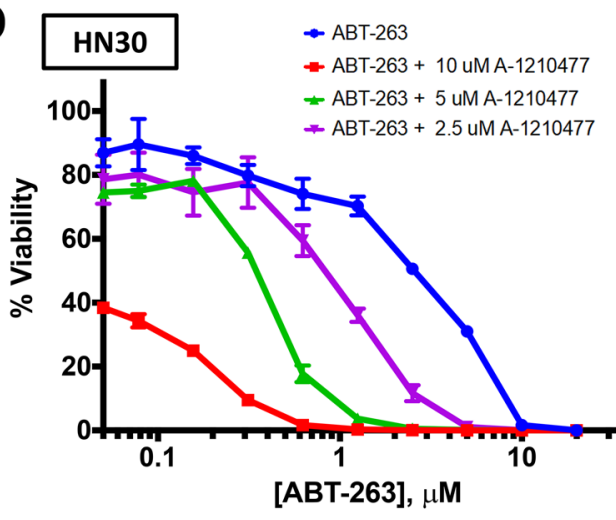

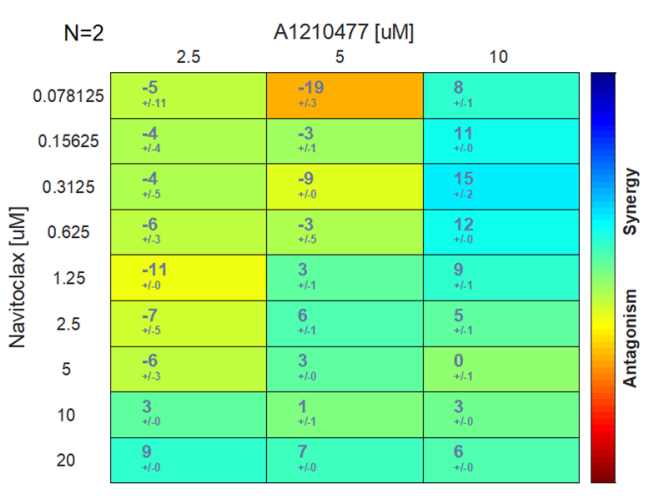
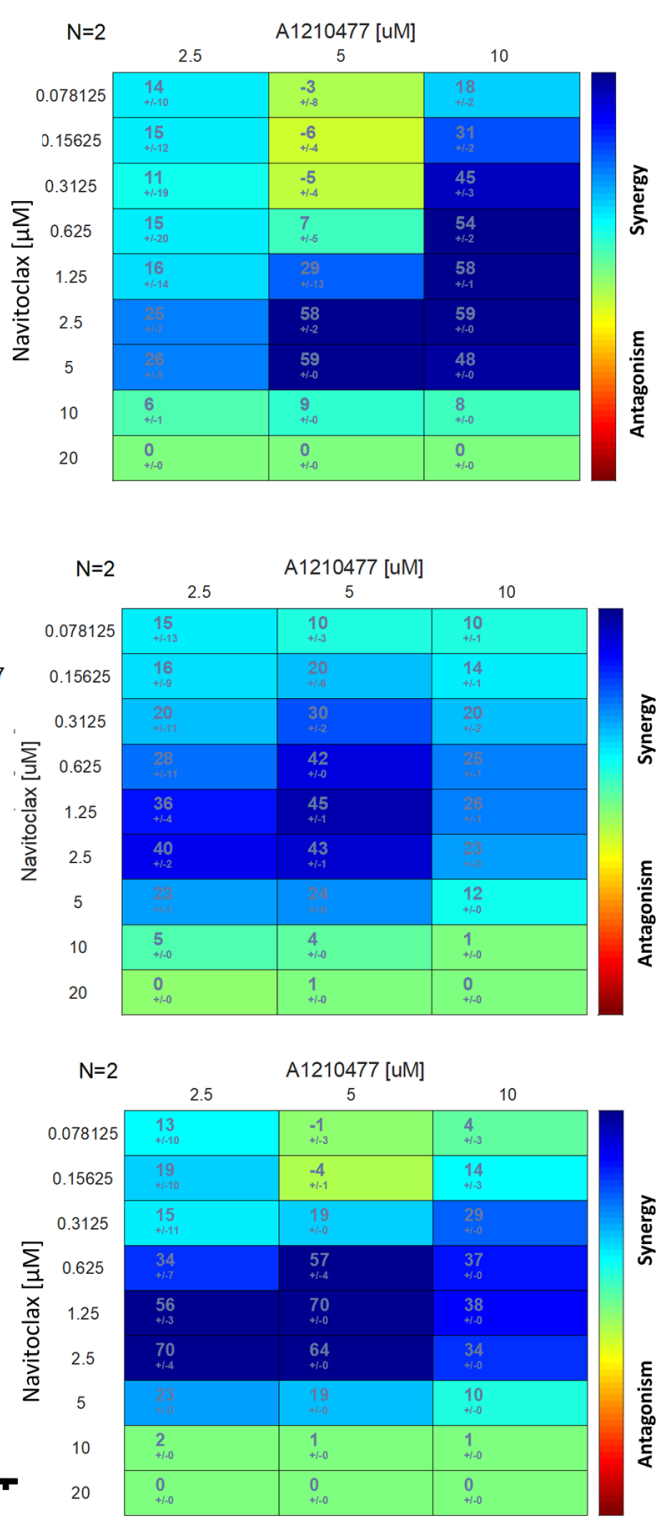

Figure 6: Bliss Independence analysis to evaluate synergistic activity between ABT-263 (navitoclax) and A-1210477. Cell viability curves and Bliss Independence analysis scores after treatment with ABT-263 (navitoclax) and A-1210477 across varying doses in PCI15B (A), Detroit 562 (B), MDA686LN (C), and HN30 (D). 
these profiles with clinical parameters, it appeared that one subgroup demonstrated improved recurrence-free survival. A follow up study by the same investigators [20] identified a 75-gene signature that could differentiate HNSCC tumors that recurred from those that did not among a test set of 40 samples from 29 patients. The predictive ability of this signature was then validated on tumors from an additional cohort of 60 patients.

While these described studies aimed to generate gene expression profiles that could stratify tumors into groups with high or low risk of recurrence, none of these profiling methods have become clinically relevant, to date. Our study attempted to use the information we gained from gene expression analysis to identify a potential strategy to better treat HNSCC tumors with high risk of treatment failure. Instead of focusing on a single gene or single pathway, we hypothesized that a strategy that would disrupt several key signaling networks identified in our analysis would prove effective. To our knowledge, we are the first to consider this approach based on a gene expression discovery analysis.

Our investigation led us to focus on BCL-xL and other BCL-2 family proteins in HNSCC. Several other groups have examined the relationship between BCL$\mathrm{xL}$ and BCL-2 in HNSCC and responses to treatment. Work by Bauer and colleagues demonstrated that patients with laryngeal SCC who express low levels of BCL$\mathrm{xL}$ demonstrate better responses to chemotherapy and chemoradiation compared to patients with high BCL-xL expression, which was recapitulated in a HNSCC cell line model examining cisplatin-resistant cells [12]. In a similar report, correlative studies from an organ-preservation trial demonstrated that high BCL-xL expression as a component of a biomarker panel was associated with poor outcomes [21]. These data generally support our findings that BCL-xL expression is an important factor differentiating HNSCC tumors that either respond or fail locoregionally after chemoradiation. BCL-2 has also been examined in HNSCC. Recent work has demonstrated that BCL-2 expression conveyed cisplatin resistance in HNSCC cell lines [14], and was independently associated with poor outcome among patients with oropharyngeal SCC after adjusting for known prognosticators, such as HPV-status, in a multivariable model [15]. Both our patient data and in vitro work suggest that BCL-xL expression is expressed at higher levels than BCL-2, and that BCL-xL (and not BCL-2) is associated with treatment response. Our in vitro data also suggest that MCL-1 expression may be an important factor associated with resistance to radiation. Large prospective studies are required to validate whether immunohistochemical expression of BCL-xL, BCL-2, and MCL-1 in pre-treatment biopsy specimens on patients with HNSCC is associated with response to radiation/ chemoradiation.

ABT-737, A BH3-mimetic small molecule that targets the BCL-2 family pro-survival proteins BCL-2,
BCL-xL, and BCL-w, was first described in 2005. This drug showed anti-tumor activity in both in vitro and in vivo models, and also enhanced the effects of both cytotoxic chemotherapeutics and radiation [22]. ABT-263 (Navitoclax), an orally bioavailable version of ABT-737, was first described in 2008, and showed preclinical activity in both B-Cell lymphoma and small cell lung cancer cells [16]. ABT-263 (navitoclax) has been studied in phase I and II trials, and the efficacy of ABT-263 (navitoclax) in solid tumors has been largely disappointing, both as a single agent $[23,24]$ and in combination with other chemotherapeutics, including gemcitabine, carboplatin/ paclitaxel, irinotecan, and erlotinib [25-28]. These studies collectively suggest that redundant anti-apoptotic mechanisms limit the efficacy of targeting BCL-2 and $\mathrm{BCL}-\mathrm{xL}$, which is consistent with our in vitro findings. The experience treating patients with HNSCC across all of these early studies has been very limited.

Therapeutics targeting BCL-2 pro-survival proteins have been tested preclinically in HNSCC. (-)-Gossypol, a BH3-mimetic which inhibits BCL-xL and BCL-2, has been studied in HNSCC cell lines, and (-)-gossypol demonstrated improved efficacy compared to cisplatin and induced apoptosis in cisplatin resistant HNSCC lines [29]. A study published in 2007 demonstrated that BH3mimetic peptides targeting BCL-xL and BCL-2 could induce apoptosis in HNSCC cell lines [30]. The same group studied ABT-737 in HNSCC cells. Similar to the findings in our study, single-agent targeting of BCL-xL/ BCL-2 had limited efficacy, while ABT-737 when applied in combination with cisplatin and etoposide appeared to have a synergistic effect and enhanced apoptosis measured by Annexin V staining and caspase cleavage [31]. Interestingly, this study showed that the cytotoxic agents resulted in down-regulation of MCL-1. Another study demonstrated that obatoclax, a proposed pan-BCL-2 inhibitor, was effective in inducing apoptosis and killing HNSCC cells [32]. However, obatoclax's mechanism of action has recently been challenged, suggesting it activates apoptosis through indirect mechanisms and does not specifically inhibit BCL-2 proteins [33]. A recent study has also demonstrated that resistance to a mammalian target of rapamycin (mTOR) inhibitor could be overcome with BCL-2 inhibition via ABT-737 treatment in a HNSCC cell line model [34]. While previous studies have examined the in vitro efficacy of BCL-2/BCL-xL inhibitors in HNSCC, both as single agents and in combination with chemotherapy, our study presents the examination of ABT263 (navitoclax) alone and in combination with cisplatin in the largest number of HNSCC cell lines reported to date. Our study is also the first to examine the combination of ABT-263 (navitoclax) with radiation therapy in HNSCC, and only the second report we could find in any tumor type. Our comprehensive evaluation led us to draw generalizable conclusions for HNSCC, specifically that targeting BCL-xL and BCL-2 alone was effective, but 
did not result in consistent synergy when combined with radiation and/or cisplatin.

The limited activity of BH3-mimetics in solid tumors, as well as our data showing that high doses of ABT-263 were necessary to achieve a response in HNSCC cells, suggest that there are redundant mechanisms that inhibit apoptosis in cancer cells. Because BCL-2 and BCL$\mathrm{xL}$ inhibitors fail to target MCL-1, MCL-1 expression is an obvious potential mechanism by which cancer cells resist treatment with $\mathrm{ABT}-263$, and this mechanism has been demonstrated in some cancer models [35, 36]. MCL-1 expression has been described in HNSCC [37], and our review of the literature only identified one brief report suggesting MCL-1 expression was associated with response to treatment in HNSCC [38]. Our examination of MCL-1 gene expression indeed showed that MCL-1 transcript levels are generally high in HNSCC tumors. Additionally, high MCL-1 expression in vitro seemed to correlate with radiation resistance. It should be noted however, that it was BCL-xL that was identified in our gene expression evaluation, and not MCL-1, that appeared to be associated with locoregional control. It is not surprising that certain gene expression transcripts are useful biomarkers because of their consistent association with certain disease phenotypes (e.g. radiation resistance) and prognosis, while other molecules are important for treatment selection, but not necessarily predictive biomarkers.

MCL-1 specific inhibitors have been discovered very recently. The first report on A-1210477 was published in 2015 by Leverson and colleagues [17] in a study that demonstrated in vitro activity as a single agent, and synergistic effect when combined with ABT-263 when applied to several cancer cell lines. Phillips and colleagues demonstrated that resistance to BCL-2 inhibition with venetoclax in non-Hodgkin's lymphoma cells could be overcome with co-treatment with A-1210477, resulting in synergy between these two drugs [39]. The interplay between MCL-1 activity and response to $\mathrm{BH} 3$-mimetics has had limited evaluation in HNSCC. As mentioned above, Li et al., demonstrated that treatment with cytotoxic agents cisplatin and etoposide led to reduced MCL-1 expression in 3 HNSCC cell lines, which perhaps influenced synergistic effects when combined with ABT-737. In our study, we did not observe synergy between cisplatin and ABT-263, however the required dose of cisplatin to achieve the IC50 was reduced in most cell lines. In our panel of HNSCC, it appeared that MCL-1 was most closely correlated with radiation resistance compared to $\mathrm{BCL}-2$ or $\mathrm{BCL}-\mathrm{xL}$ expression, and combining inhibition of MCL-1 with ABT-263 demonstrated consistently improved efficacy, and synergy based on Bliss Independence analysis.

Our study represents a preliminary look at the complex interplay between apoptosis signaling molecules in HNSCC, and the authors recognize several limitations of our report. First, we acknowledge that the cohort of patients examined in our study is heterogenous, and that the definitions we applied for failure and response to treatment is perhaps unconventional. However, we placed careful restrictions and definitions to the discovery set in order to focus on the biology of resistance to non-surgical treatment. We also recognize that evidence of treatment responses in an in vivo model would best support our findings, and these studies are planned. To our knowledge, this study is the first to examine the combination of ABT263 with an MCL-1 inhibitor in HNSCC. A-1210477 was selected as it was the earliest available MCL-1 inhibitor available for the studies in this report. This agent cannot be used in vivo due to the pharmacokinetic profile of this molecule [40], but other options now exist for inhibition of MCL-1. A recent study reported that afatanib, a dual EGFR and HER2 inhibitor, decreases MCL-1 expression in HNSCC cells [41]. Very recently a new MCL-1 inhibitor, S63845, was described and demonstrated both in vitro and in vivo efficacy against MCL-1 dependent myeloma, leukemia, and lymphoma cells [42]. This report also examined effects of this inhibitor with several other chemotherapeutic agents in solid tumor cell lines. Based on the data we have presented here, the combination of improved and clinically applicable MCL-1 inhibitors, such as S63845, with drugs targeting BCL-xL/BCL2, is a logical and potentially effective next step for in vivo studies of HNSCC.

In conclusion, expression of the BCL-2 family prosurvival molecule BCL-xL was a component of several gene networks identified after profiling treatment-resistant and treatment-sensitive HNSCC tumors. Inhibition of BCL-xL with ABT-263 (navitoclax) demonstrated consistent efficacy in HNSCC cells, but at relatively high doses. MCL-1 expression correlated with radiation resistance in HNSCC cells, and inhibition of MCL-1 with A-1210477 enhanced response to ABT-263 (navitoclax). Increasing clinical experience with $\mathrm{BH} 3$-mimetic agents, and newly characterized agents targeting MCL-1 may lead to novel and effective strategies targeting HNSCC.

\section{MATERIALS AND METHODS}

\section{Patient cohort}

Patients with newly diagnosed HNSCC were enrolled on an ongoing IRB-approved prospective cohort study and tumor banking program at our institution, as previously described [43, 44]. For this study, patients were enrolled and followed between 2002 - 2014. After obtaining written consent for participation, histologically confirmed HNSCC tumors were obtained by biopsy or surgical resection from patients undergoing treatment at Montefiore Medical Center in Bronx, New York. The specimen submitted for RNA extraction was procured from tissue deemed to be grossly viable tumor (areas of normal 
mucosa or gross necrosis were avoided) by the operating surgeon and/or pathologist. Tumors were snap frozen in liquid nitrogen within 30 minutes of procurement. Each tumor was assessed by a clinical pathologist to confirm diagnosis of HNSCC, and to measure percent tumor of each sample on a representative histologic section using hematoxylin and eosin staining. Details regarding tumor acquisition, pathologic confirmation and tumor content have been previously published $[45,46]$. Patients were selected for this study by identifying patients who failed after treatment compared to those who remained free of locoregional recurrence after treatment according to the following criteria:

\section{Inclusion criteria}

Patients were required to have been diagnosed with squamous cell carcinoma with a primary tumor site in the upper aerodigestive tract. All patients were required to have undergone diagnostic biopsy and/or initial treatment for HNSCC at Montefiore Medical Center. Cases were defined as treatment failures if they received radiation or chemoradiation to treat their disease, and subsequently failed treatment with persistent or recurrent local (primary site) or regional (neck lymph node) disease in the treated field. Patients who also received surgery with subsequent radiation or chemoradiation were included among the treatment failure group, as locoregional failure in these cases were considered disease that resisted non-surgical therapy. Patients were defined as treatment responders if they received primary radiation or chemoradiation and experienced a complete response, with no documented local or regional recurrence at the last follow up at the time of analysis.

\section{Exclusion criteria}

Of note, subjects who received surgical resection as a component of their primary treatment were not included in the treatment responder group, in order to enrich this group for those tumors with complete response to and no recurrence after non-surgical treatment.

Patients with non-squamous cell cancer histology (eg. salivary gland carcinoma), and patients with primary tumors located in sites other than the upper aerodigestive tract (eg. cutaneous cancers) were excluded. Patients with primary cancer of the nasopharynx and paranasal sinuses were also excluded. Also, patients who underwent treatment for a previous head and neck cancer (ie. enrolled at diagnosis of a second or subsequent primary HNSCC), and those who were enrolled at the time of HNSCC recurrence were also excluded.

Figure 1A illustrates the selection process for inclusion and exclusion in the discovery analysis.

\section{Gene expression analysis}

Total RNA was extracted from tumor tissue using TRIzol $^{\mathrm{TM}}$ by a standardized protocol (Invitrogen ${ }^{\mathrm{TM}}$,
Carlsbad, CA). RNA was collected by alcohol precipitation and quantitated for microarray analysis. Quality control was performed on selected samples, checking for integrity of RNAs using an Agilent 2100 bioanalyzer (Agilent, Santa Clara, CA) and RNA pico chips as described by the manufacturer. Total RNA (500 ng) was amplified and biotin labeled with the Illumina ${ }^{\circledR}$ TotalPrep ${ }^{\text {TM }}$ RNA Amplification Kit (Ambion ${ }^{\circledR}$, Austin, Texas). Global expression was analyzed by RNA hybridization to the Illumina ${ }^{\circledR}$ HumanHT-12-v3 Expression BeadChip (Illumina $^{\circledR}$, San Diego, California). Probes were matched to known genes and alternative splice variants using the RefSeq database release 17 (https://www.ncbi.nlm.nih. gov/refseq/) and UniGene build 188 (https://www.ncbi. nlm.nih.gov/unigene). Controls for each RNA sample were used to confirm RNA quality, biotin labeling success, hybridization stringency, and signal levels.

\section{Bioinformatic analysis}

Microarray expression values were quantile normalized within BeadStudio (Illumina ${ }^{\circledR}$ ) prior to analysis. Expression data were batch corrected using the ComBat function from the sva R package [47]. Supervised analysis using sparse Partial Least Squares-Discriminant Analysis (sPLS-DA) [48] was carried out to identify a set of gene expression biomarkers that differentiated the failure and responder groups. The sPLS-DA model was tuned using different combinations of parameters, namely, number of model components (1-10) and number of selected features (probesets) on each component (100500). Model validation was carried out using leave-one-out crossvalidation (LOOCV) with the lowest predictive error being achieved using a 2-component model and selecting 100 features on each component. Genes identified as differentiating these two groups were analyzed using Ingenuity $^{\circledR}$ Pathway Analysis (IPA) (QIAGEN, Hilden, Germany).

\section{HNSCC cell culture}

HNSCC cell lines HN30, HN31, PCI15A, PCI15B, UMSCC6, MDA686LN, and HN5, were obtained from a repository maintained by Dr. Jeffrey N. Myers, MD, $\mathrm{PhD}$ at the University of Texas, MD Anderson Cancer Center, with some cell lines requiring the following permissions (HN30, HN31 - John Ensley, MD, Wayne State University; PCI-15A, PCI15B - Jennifer Grandis, MD, University of Pittsburgh; UMSCC6 - Thomas Carey, University of Michigan; MDA686LN - Peter Sacks, MD, New York University/University of Texas MD Anderson Cancer Center). The Detroit562 cell line was acquired from the American Type Culture Collection. All cells were maintained in Dulbecco's Modified Eagle's Medium (DMEM) supplemented with 10\% Fetal Bovine Serum (FBS), nonessential amino acids, sodium pryuvate and 1\% antibiotic — penicillin/strepomycin. Cells were incubated 
at $37^{\circ} \mathrm{C}, 5 \% \mathrm{CO}_{2}$. These $8 \mathrm{HNSCC}$ cell lines were used in all of the in vitro assays described. Stock samples for all cell lines used were authenticated with short tandem repeat (STR) genotyping. All experiments were performed within 20 or less passages for each line.

\section{Clonogenic survival assays ( $\gamma$-irradiation)}

Cells were seeded onto 6-well plates at densities of $800-1600$ cells/well, 24 hours before treatment. At $24 \mathrm{hrs}$ cells were treated with $\gamma$-irradiation (Cesium-137, $2 \mathrm{~Gy} / \mathrm{min}$ ) at indicated doses and returned to $37^{\circ} \mathrm{C}$ incubation. After 5 days media was replaced with fresh media, and cells were allowed to continue growth. Colony growth continued to be monitored up to $5-14$ days post $\gamma$-irradiation. At the time of harvest, media was removed and cell clones were washed, fixed, and stained with $0.25 \%$ Cresyl Violet. The results were quantified with ImageJ software [49]. Plating efficiency was optimized for each cell line, and surviving fractions were calculated per standard methods [50]. To establish radiation or combination drug-radiation sensitivity, assays were carried out in triplicate.

\section{Clonogenic survival assays combining ABT-263 treatment and radiation}

Cells were seeded into 6-well plates as described above. Cells were pre-treated with ABT-263 for 4 hours before $\gamma$-irradiation (Cesium-137, 2Gy/min, JL Shepherd Mark I Model 68 Irradiator, JL Shepherd and Associates, San Fernando, CA). Harvest and survival calculations were carried out as described above. Experiments were performed in duplicate and not repeated a third time after preliminary results demonstrated little benefit with combination treatment.

\section{Western blot}

Cells grown in vitro were washed with PBS, scraped from cell culture plates, and lysed using standard RIPA buffer. Protein concentrations of cell lysates were determined by Lowry Protein Assay (BioRad Laboratories, Hercules, CA). Equal amounts of proteins were loaded onto SDS-PAGE gels, separated by electrophoresis, and transferred onto PVDF membranes. Membranes were washed in TBS-T and blocked in $1 \%$ $\mathrm{BSA}$ at room temperature for 1 hour or in $4^{\circ} \mathrm{C}$ overnight. The membrane was probed overnight at $4^{\circ} \mathrm{C}$ with primary antibody. Then it was washed and incubated with appropriate secondary antibody. Membranes were probed using the following antibodies: BCL-2, BCL-xL, MCL-1 (Cell Signaling Technology, Danvers, MA), each at 1:500 dilution and Beta-Actin as a loading control protein (Santa Cruz Biotechnology, Dallas, Tx) at 1:10,000 dilution. Following fluorescent secondary antibody incubation at 1:2500 dilution, immunoreactive proteins were visualized with the LI-COR ${ }^{\circledR}$ Odyssey ${ }^{\circledR}$ FC Imaging System. Protein band quantification was determined with image studio software (LI-COR ${ }^{\circledR}$ Biosciences, Lincoln, NE). All protein quantification experiments were carried out on a minimum of three representative western blots.

\section{Cell viability assays (MTT)}

All cell lines were plated on 96-well plates at 1,500 cells/well (UMSCC6 at 4,000 cells/well). Cells were incubated for 24 hours before drug addition. Incubation time was maintained between 48 - 72 hours for each condition. Conditions were optimized for each condition. Cell death was generally more rapid when cisplatin treatment was included. Specifically, incubation time for Cisplatin alone was 48hrs, ABT-263 (navitoclax) alone was $72 \mathrm{hrs}$, Cisplatin and ABT-263 (navitoclax) was 48 hrs, A-1210477 was 72 hrs and ABT-263 (navitoclax) plus A-1210477 was 72 hrs All drugs were initially dissolved in dimethyl sulfoxide (DMSO), and thus control (untreated) wells were maintained in corresponding dilutions of dissolvent DMSO. After drug incubation, MTT 3-(4,5-dimethylthiazol-2-yl)-2,5-diphenyltetrazolium bromide) was added until visualization of formazan crystals, approximately 180 minutes. All media was then aspirated from wells, and the cells were lysed in $100 \mu \mathrm{L}$ of DMSO on an orbital pulse shaker. Approximate viability was determined with Benchmark Plus ${ }^{\mathrm{TM}}$ Microplate Spectrophotometer System (Bio-Rad, Laboratories, Hercules, CA) at $570 \mathrm{~nm}$. The percentage of growth rates were calculated relative to the untreated control and were graphed as a function of the $\log _{10}$ concentration. IC50 values were calculated by non-linear regression fourparameter logistics curve analysis with GraphPad Prism (GraphPad Software, La Jolla, CA). All MTT assays were repeated in triplicate.

\section{Cell viability assays for Bliss Independence analysis}

HNCC cells (1500 cells/well) were seeded in 96-well white plates. Cells were incubated with serial dilutions of ABT-263 (20 mM to $0.078 \mathrm{mM})$ and cotreated with A1210477 at the indicated concentrations. Control (untreated) wells were maintained in corresponding dilutions of dissolvent DMSO. Cell viability was assayed after 72 hours treatment using the Cell Titer-Glo (Promega, Madison, WI), according to the manufacturer's protocol. Luminescence was measured using the TECAN M200 microplate reader. Viability assays were performed in duplicates and the data normalized to vehicle-treated control wells. IC50 values were determined by nonlinear regression analysis using Prism software (GraphPad Software, La Jolla, CA). The Bliss Independence combination synergy was assessed using the Combenefit platform as previously described in Veroli et al. Bioinformatics 2016. [51] 


\section{Statistical analysis}

Bioinformatic analysis carried out on the patient cohort is described in a preceding section. Descriptions and references for calculations for plating efficiency/ surviving fraction, IC50 calculations, and Bliss Independence analysis are described in their respective sections above. Mean averages and standard deviation (SD) or standard error of the mean (SEM) were used to present normally distributed data, where appropriate (i.e. average surviving fraction after radiation, average IC50 for MTT assays, average fold increase in MCL-1 expression on Western blot). Median average and interquartile ranges (IQR, 25\%, 75\%) were calculated for gene expression levels of BCL-xL, MCL-1 and BCL2, and comparisons between responders and failure subjects were carried out using Mann-Whitney $U$ tests. Paired $T$-tests were used to compare expression of BCL-xL and MCL-1 in HNSCC cell lines before and after treatment with ABT-263 (navitoclax). A two-sided p-value $<0.05$ was considered statistically significant for all statistical calculations.

\section{Abbreviations}

AJCC - American Joint Committee on Cancer

BSA - bovine serum albumin

DMEM - Dubelcco's modified Eagle's medium

DNA - deoxyribonucleic acid

HNSCC - head and neck squamous cell carcinoma

Gy - Gray

HPV - human papillomavirus

hrs - hours

IC50 - half maximal inhibitory concentration

IQR - interquartile range

IPA - Ingenuity Pathway Analysis

LOOCV - leave one out cross-validation

MTT - 3-(4,5-dimethylthiazol-2-yl)-2,5-dipheny-

ltetrazolium bromide

ng - nanogram

$\mathrm{nm}$ - nanometer

PBS - phosphate buffered saline

PVDF - polyvinylidene fluoride

RIPA - radioimmunoprecipitation assay

RNA - ribonucleic acid

SCC - squamous cell carcinoma

$\mathrm{SD}$ - standard deviation

SDS-PAGE - sodium dodecyl sulphatepolyacrylamide gel electrophoresis

SEM - standard error of the mean

sPLS-DA - sparse partial least squares discriminant analysis

$\mu \mathrm{M}$ - micromolar

TBS-T - tris-buffered saline - Polysorbate 20

(Tween 20)

$\mu \mathrm{L}$ - microliter

\section{Author contributions}

TJO - Study design, acquisition of data, analysis and interpretation of data, drafting manuscript, revising manuscript, final approval of manuscript

CDF - Study design, acquisition of data, analysis and interpretation of data, drafting manuscript, revising manuscript, final approval of manuscript

CT - Study design, acquisition of data, analysis and interpretation of data, drafting manuscript, revising manuscript, final approval of manuscript

POB - Study design, analysis and interpretation of data, drafting manuscript, revising manuscript, final approval of manuscript

$\mathrm{AL}$ - acquisition of data, analysis and interpretation of data, revising manuscript, final approval of manuscript

DER - acquisition of data, analysis and interpretation of data, revising manuscript, final approval of manuscript

RVS - acquisition of data, revising manuscript, final approval of manuscript

CS - acquisition of data, revising manuscript, final approval of manuscript

MBP - acquisition of data, analysis and interpretation of data, revising manuscript, final approval of manuscript

NFS - acquisition of data, analysis and interpretation of data, revising manuscript, final approval of manuscript

BAS - acquisition of data, revising manuscript, final approval of manuscript

GR - acquisition of data, revising manuscript, final approval of manuscript $\mid$

TJB - acquisition of data, revising manuscript, final approval of manuscript

TMH - acquisition of data, revising manuscript, final approval of manuscript

GCC - acquisition of data, revising manuscript, final approval of manuscript

NK - acquisition of data, revising manuscript, final approval of manuscript

CG - Study design, analysis and interpretation of data, drafting manuscript, revising manuscript, final approval of manuscript

EG - Study design, analysis and interpretation of data, revising manuscript, final approval of manuscript

\section{ACKNOWLEDGMENTS}

The authors would like to thank the laboratory of Jeffrey N. Myers for graciously providing the cell lines used in this work.

\section{CONFLICTS OF INTEREST}

The authors declare no potential conflicts of interest. 


\section{FUNDING}

Thomas J. Ow's contribution was supported in part by NIH-NCI grant 2K12 CA132783-06, the Triological Society Career Development Award, NIH-NIDCR grant 1 K23 DE027425-01, and by NIH/National Center for Advancing Translational Science (NCATS) EinsteinMontefiore Clinical Translational Science Award (CTSA) Grant Number UL1TR001073. E.G and D.E.R were supported from NIH-NCI grant CA178394 and an award from the Pershing Square Sohn Cancer Research Alliance. AL was supported from a T32 Training grant T32 AG 23475. The authors also acknowledge support from the Albert Einstein Cancer Center (NIH-NCI P30CA013330) and Roswell Park Comprehensive Cancer Center (NIHNCI P30CA016056). The manuscript content is solely the responsibility of the authors and do not necessarily represent the official views of the National Institute of Health (NIH).

\section{REFERENCES}

1. Siegel RL, Miller KD, Jemal A. Cancer statistics, 2016. CA Cancer J Clin. 2016; 66:7-30. https://doi.org/10.3322/caac.21332.

2. Ferlay J, Soerjomataram I, Dikshit R, Eser S, Mathers C, Rebelo M, Parkin DM, Forman D, Bray F. Cancer incidence and mortality worldwide: sources, methods and major patterns in GLOBOCAN 2012. Int J Cancer. 2015; 136:E359-86. https://doi.org/10.1002/ijc.29210.

3. Zhen W, Karnell LH, Hoffman HT, Funk GF, Buatti JM, Menck HR. The National Cancer Data Base report on squamous cell carcinoma of the base of tongue. Head Neck. 2004; 26:660-74. https://doi.org/10.1002/hed.20064.

4. Tiwana MS, Wu J, Hay J, Wong F, Cheung W, Olson RA. 25 year survival outcomes for squamous cell carcinomas of the head and neck: population-based outcomes from a Canadian province. Oral Oncol. 2014; 50:651-56. https://doi.org/10.1016/j.oraloncology.2014.03.009.

5. Funk GF, Karnell LH, Robinson RA, Zhen WK, Trask DK, Hoffman HT. Presentation, treatment, and outcome of oral cavity cancer: a National Cancer Data Base report. Head Neck. 2002; 24:165-80. https://doi.org/10.1002/hed.10004.

6. Forastiere AA, Goepfert H, Maor M, Pajak TF, Weber R, Morrison W, Glisson B, Trotti A, Ridge JA, Chao C, Peters G, Lee DJ, Leaf A, et al. Concurrent chemotherapy and radiotherapy for organ preservation in advanced laryngeal cancer. N Engl J Med. 2003; 349:2091-98. https://doi.org/10.1056/NEJMoa031317.

7. Ang KK, Harris J, Wheeler R, Weber R, Rosenthal DI, Nguyen-Tân PF, Westra WH, Chung CH, Jordan RC, Lu C, Kim H, Axelrod R, Silverman CC, et al. Human papillomavirus and survival of patients with oropharyngeal cancer. N Engl J Med. 2010; 363:24-35. https://doi.org/10.1056/NEJMoa0912217.
8. Cooper JS, Pajak TF, Forastiere AA, Jacobs J, Campbell BH, Saxman SB, Kish JA, Kim HE, Cmelak AJ, Rotman M, Machtay M, Ensley JF, Chao KS, et al, and Radiation Therapy Oncology Group 9501/ Intergroup. Postoperative concurrent radiotherapy and chemotherapy for high-risk squamous-cell carcinoma of the head and neck. N Engl J Med. 2004; 350:1937-44. https://doi.org/10.1056/NEJMoa032646.

9. Hanahan D, Weinberg RA. The hallmarks of cancer. Cell. 2000; 100:57-70. https://doi.org/10.1016/S0092-8674(00)81683-9.

10. Czabotar PE, Lessene G, Strasser A, Adams JM. Control of apoptosis by the BCL-2 protein family: implications for physiology and therapy. Nat Rev Mol Cell Biol. 2014; 15:49-63. https://doi.org/10.1038/nrm3722.

11. Reed JC. Regulation of apoptosis by bcl-2 family proteins and its role in cancer and chemoresistance. Curr Opin Oncol. 1995; 7:541-46. https://doi.org/10.1097/00001622-199511000-00012.

12. Bauer JA, Kumar B, Cordell KG, Prince ME, Tran HH, Wolf GT, Chepeha DB, Teknos TN, Wang S, Eisbruch A, Tsien CI, Urba SG, Worden FP, et al. Targeting apoptosis to overcome cisplatin resistance: a translational study in head and neck cancer. Int J Radiat Oncol Biol Phys. 2007; 69:S106-08. https://doi.org/10.1016/j.ijrobp.2007.05.080.

13. Wolter KG, Wang SJ, Henson BS, Wang S, Griffith KA, Kumar B, Chen J, Carey TE, Bradford CR, D'Silva NJ. (-)-gossypol inhibits growth and promotes apoptosis of human head and neck squamous cell carcinoma in vivo. Neoplasia. 2006; 8:163-72. https://doi.org/10.1593/neo.05691.

14. Michaud WA, Nichols AC, Mroz EA, Faquin WC, Clark JR, Begum S, Westra WH, Wada H, Busse PM, Ellisen LW, Rocco JW. Bcl-2 blocks cisplatin-induced apoptosis and predicts poor outcome following chemoradiation treatment in advanced oropharyngeal squamous cell carcinoma. Clin Cancer Res. 2009; 15:1645-54. https://doi.org/10.1158/1078-0432.CCR-08-2581.

15. Nichols AC, Finkelstein DM, Faquin WC, Westra WH, Mroz EA, Kneuertz P, Begum S, Michaud WA, Busse PM, Clark JR, Rocco JW. Bcl2 and human papilloma virus 16 as predictors of outcome following concurrent chemoradiation for advanced oropharyngeal cancer. Clin Cancer Res. 2010; 16:2138-46. https://doi.org/10.1158/1078-0432.CCR-09-3185.

16. Tse C, Shoemaker AR, Adickes J, Anderson MG, Chen J, Jin S, Johnson EF, Marsh KC, Mitten MJ, Nimmer P, Roberts L, Tahir SK, Xiao Y, et al. ABT-263: a potent and orally bioavailable Bcl-2 family inhibitor. Cancer Res. 2008; 68:3421-28. https://doi.org/10.1158/0008-5472.CAN-07-5836.

17. Leverson JD, Zhang H, Chen J, Tahir SK, Phillips DC, Xue J, Nimmer P, Jin S, Smith M, Xiao Y, Kovar P, Tanaka A, Bruncko M, et al. Potent and selective smallmolecule MCL-1 inhibitors demonstrate on-target cancer cell killing activity as single agents and in combination 
with ABT-263 (navitoclax). Cell Death Dis. 2015; 6:e1590. https://doi.org/10.1038/cddis.2014.561.

18. Ginos MA, Page GP, Michalowicz BS, Patel KJ, Volker SE, Pambuccian SE, Ondrey FG, Adams GL, Gaffney PM. Identification of a gene expression signature associated with recurrent disease in squamous cell carcinoma of the head and neck. Cancer Res. 2004; 64:55-63. https://doi.org/10.1158/0008-5472.CAN-03-2144.

19. Chung CH, Parker JS, Karaca G, Wu J, Funkhouser WK, Moore D, Butterfoss D, Xiang D, Zanation A, Yin X, Shockley WW, Weissler MC, Dressler LG, et al. Molecular classification of head and neck squamous cell carcinomas using patterns of gene expression. Cancer Cell. 2004; 5:489500. https://doi.org/10.1016/S1535-6108(04)00112-6.

20. Chung CH, Parker JS, Ely K, Carter J, Yi Y, Murphy BA, Ang KK, El-Naggar AK, Zanation AM, Cmelak AJ, Levy S, Slebos RJ, Yarbrough WG. Gene expression profiles identify epithelial-to-mesenchymal transition and activation of nuclear factor-kappaB signaling as characteristics of a high-risk head and neck squamous cell carcinoma. Cancer Res. 2006; 66:8210-18. https://doi.org/10.1158/0008-5472.CAN-06-1213.

21. Kumar B, Cordell KG, Lee JS, Worden FP, Prince ME, Tran HH, Wolf GT, Urba SG, Chepeha DB, Teknos TN, Eisbruch A, Tsien CI, Taylor JM, et al. EGFR, p16, HPV Titer, Bcl-xL and p53, sex, and smoking as indicators of response to therapy and survival in oropharyngeal cancer. J Clin Oncol. 2008; 26:3128-37. https://doi.org/10.1200/JCO.2007.12.7662.

22. Oltersdorf T, Elmore SW, Shoemaker AR, Armstrong RC, Augeri DJ, Belli BA, Bruncko M, Deckwerth TL, Dinges J, Hajduk PJ, Joseph MK, Kitada S, Korsmeyer SJ, et al. An inhibitor of Bcl-2 family proteins induces regression of solid tumours. Nature. 2005; 435:677-81. https://doi.org/10.1038/nature03579.

23. Gandhi L, Camidge DR, Ribeiro de Oliveira M, Bonomi P, Gandara D, Khaira D, Hann CL, McKeegan EM, Litvinovich E, Hemken PM, Dive C, Enschede SH, Nolan C, et al. Phase I study of Navitoclax (ABT-263), a novel Bcl-2 family inhibitor, in patients with small-cell lung cancer and other solid tumors. J Clin Oncol. 2011; 29:90916. https://doi.org/10.1200/JCO.2010.31.6208.

24. Rudin CM, Hann CL, Garon EB, Ribeiro de Oliveira M, Bonomi PD, Camidge DR, Chu Q, Giaccone G, Khaira D, Ramalingam SS, Ranson MR, Dive C, McKeegan EM, et al. Phase II study of single-agent navitoclax (ABT-263) and biomarker correlates in patients with relapsed small cell lung cancer. Clin Cancer Res. 2012; 18:3163-9. https://doi.org/10.1158/1078-0432.CCR-11-3090.

25. Vlahovic G, Karantza V, Wang D, Cosgrove D, Rudersdorf N, Yang J, Xiong H, Busman T, Mabry M. A phase I safety and pharmacokinetic study of ABT-263 in combination with carboplatin/paclitaxel in the treatment of patients with solid tumors. Invest New Drugs. 2014; 32:976-84. https://doi.org/10.1007/s10637-014-0116-3.

26. Cleary JM, Lima CM, Hurwitz HI, Montero AJ, Franklin C, Yang J, Graham A, Busman T, Mabry M, Holen K, Shapiro GI, Uronis H. A phase I clinical trial of navitoclax, a targeted high-affinity $\mathrm{Bcl}-2$ family inhibitor, in combination with gemcitabine in patients with solid tumors. Invest New Drugs. 2014; 32:937-45. https://doi.org/10.1007/s10637-014-0110-9.

27. Tolcher AW, LoRusso P, Arzt J, Busman TA, Lian G, Rudersdorf NS, Vanderwal CA, Kirschbrown W, Holen KD, Rosen LS. Safety, efficacy, and pharmacokinetics of navitoclax (ABT-263) in combination with erlotinib in patients with advanced solid tumors. Cancer Chemother Pharmacol. 2015; 76:1025-32. https://doi.org/10.1007/s00280-015-2883-8.

28. Tolcher AW, LoRusso P, Arzt J, Busman TA, Lian G, Rudersdorf NS, Vanderwal CA, Waring JF, Yang J, Holen KD, Rosen LS. Safety, efficacy, and pharmacokinetics of navitoclax (ABT-263) in combination with irinotecan: results of an open-label, phase 1 study. Cancer Chemother Pharmacol. 2015; 76:1041-49. https://doi.org/10.1007/s00280-015-2882-9.

29. Bauer JA, Trask DK, Kumar B, Los G, Castro J, Lee JS, Chen J, Wang S, Bradford CR, Carey TE. Reversal of cisplatin resistance with a $\mathrm{BH} 3$ mimetic, (-)-gossypol, in head and neck cancer cells: role of wild-type p53 and Bcl-xL. Mol Cancer Ther. 2005; 4:1096-104. https://doi.org/10.1158/1535-7163.MCT-05-0081.

30. Li R, Boehm AL, Miranda MB, Shangary S, Grandis JR, Johnson DE. Targeting antiapoptotic Bcl-2 family members with cell-permeable $\mathrm{BH} 3$ peptides induces apoptosis signaling and death in head and neck squamous cell carcinoma cells. Neoplasia. 2007; 9:801-11. https://doi.org/10.1593/neo.07394.

31. Li R, Zang Y, Li C, Patel NS, Grandis JR, Johnson DE. ABT-737 synergizes with chemotherapy to kill head and neck squamous cell carcinoma cells via a Noxamediated pathway. Mol Pharmacol. 2009; 75:1231-39. https://doi.org/10.1124/mol.108.052969.

32. Yazbeck VY, Li C, Grandis JR, Zang Y, Johnson DE. Single-agent obatoclax (GX15-070) potently induces apoptosis and pro-survival autophagy in head and neck squamous cell carcinoma cells. Oral Oncol. 2014; 50:120 27. https://doi.org/10.1016/j.oraloncology.2013.10.013.

33. S Soderquist R, Eastman A. BCL2 Inhibitors as Anticancer Drugs: A Plethora of Misleading BH3 Mimetics. Mol Cancer Ther. 2016; 15:2011-17. https://doi.org/10.1158/1535-7163.MCT-16-0031.

34. Li Y, Cui JT. Inhibition of Bcl-2 potentiates AZD-2014induced anti-head and neck squamous cell carcinoma cell activity. Biochem Biophys Res Commun. 2016; 477:60713. https://doi.org/10.1016/j.bbrc.2016.06.100. 
35. Boiani M, Daniel C, Liu X, Hogarty MD, Marnett LJ. The stress protein BAG3 stabilizes Mcl-1 protein and promotes survival of cancer cells and resistance to antagonist ABT-737. J Biol Chem. 2013; 288:6980-90. https://doi.org/10.1074/jbc.M112.414177.

36. Punnoose EA, Leverson JD, Peale F, Boghaert ER, Belmont LD, Tan N, Young A, Mitten M, Ingalla E, Darbonne WC, Oleksijew A, Tapang P, Yue P, et al. Expression Profile of BCL-2, BCL-XL, and MCL-1 Predicts Pharmacological Response to the BCL-2 Selective Antagonist Venetoclax in Multiple Myeloma Models. Mol Cancer Ther. 2016; 15:1132-44. https://doi.org/10.1158/1535-7163.MCT-15-0730.

37. Hotz MA, Bosq J, Zbaeren P, Reed J, Schwab G, Krajewski S, Brousset P, Borner MM. Spontaneous apoptosis and the expression of p53 and Bcl-2 family proteins in locally advanced head and neck cancer. Arch Otolaryngol Head Neck Surg. 1999; 125:417-22. https://doi.org/10.1001/archotol.125.4.417.

38. Erovic BM, Pelzmann M, Grasl MCh, Pammer J, Kornek G, Brannath W, Selzer E, Thurnher D. Mcl1, vascular endothelial growth factor-R2, and 14-33 sigma expression might predict primary response against radiotherapy and chemotherapy in patients with locally advanced squamous cell carcinomas of the head and neck. Clin Cancer Res. 2005; 11:8632-6. https://doi.org/10.1158/1078-0432.CCR-05-1170.

39. Phillips DC, Xiao Y, Lam LT, Litvinovich E, RobertsRapp L, Souers AJ, Leverson JD. Loss in MCL-1 function sensitizes non-Hodgkin's lymphoma cell lines to the BCL2-selective inhibitor venetoclax (ABT-199). Blood Cancer J. 2015; 5:e368. https://doi.org/10.1038/bcj.2015.88. Erratum in: Loss in MCL-1 function sensitizes non-Hodgkin's lymphoma cell lines to the BCL-2-selective inhibitor venetoclax (ABT-199). [Blood Cancer J. 2016].

40. Opferman JT. Attacking cancer's Achilles heel: antagonism of anti-apoptotic BCL-2 family members. FEBS J. 2016; 283:2661-75. https://doi.org/10.1111/febs.13472.

41. Liu X, Lv Z, Zou J, Liu X, Ma J, Wang J, Sa N, Jing P, $\mathrm{Xu}$ W. Afatinib down-regulates MCL-1 expression through the PERK-eIF2 $\alpha$-ATF4 axis and leads to apoptosis in head and neck squamous cell carcinoma. Am J Cancer Res. 2016; 6:1708-19.

42. Kotschy A, Szlavik Z, Murray J, Davidson J, Maragno AL, Le Toumelin-Braizat G, Chanrion M, Kelly GL, Gong JN, Moujalled DM, Bruno A, Csekei M, Paczal A, et al. The MCL1 inhibitor S63845 is tolerable and effective in diverse cancer models. Nature. 2016; 538:477-82. https://doi.org/10.1038/nature19830.

43. Belbin TJ, Bergman A, Brandwein-Gensler M, Chen Q, Childs G, Garg M, Haigentz M, Hogue-Angeletti R, Moadel R, Negassa A, Owen R, Prystowsky MB, Schiff B, et al. Head and neck cancer: reduce and integrate for optimal outcome. Cytogenet Genome Res. 2007; 118:92-109. https://doi.org/10.1159/000108290.

44. Belbin TJ, Schlecht NF, Smith RV, Adrien LR, Kawachi N, Brandwein-Gensler M, Bergman A, Chen Q, Childs G, Prystowsky MB. Site-specific molecular signatures predict aggressive disease in HNSCC. Head Neck Pathol. 2008; 2:243-56. https://doi.org/10.1007/s12105-008-0071-4.

45. Lleras RA, Adrien LR, Smith RV, Brown B, Jivraj N, Keller C, Sarta C, Schlecht NF, Harris TM, Childs G, Prystowsky MB, Belbin TJ. Hypermethylation of a cluster of Krüppel-type zinc finger protein genes on chromosome 19q13 in oropharyngeal squamous cell carcinoma. Am J Pathol. 2011; 178:1965-74. https://doi.org/10.1016/j.ajpath.2011.01.049.

46. Lleras RA, Smith RV, Adrien LR, Schlecht NF, Burk RD, Harris TM, Childs G, Prystowsky MB, Belbin TJ. Unique DNA methylation loci distinguish anatomic site and HPV status in head and neck squamous cell carcinoma. Clin Cancer Res. 2013; 19:5444-55. https://doi.org/10.1158/1078-0432.CCR-12-3280.

47. Leek JT, Johnson WE, Parker HS, Fertig EJ, Jaffe AE, Storey JD. sva: Surrogate Variable Analysis. R package version 3.12.0.

48. Lê Cao KA, Boitard S, Besse P. Sparse PLS discriminant analysis: biologically relevant feature selection and graphical displays for multiclass problems. BMC Bioinformatics. 2011; 12:253. https://doi.org/10.1186/1471-2105-12-253.

49. Schneider CA, Rasband WS, Eliceiri KW. NIH Image to ImageJ: 25 years of image analysis. Nat Methods. 2012; 9:671-75. https://doi.org/10.1038/nmeth.2089.

50. Franken NA, Rodermond HM, Stap J, Haveman J, van Bree C. Clonogenic assay of cells in vitro. Nat Protoc. 2006; 1:2315-19. https://doi.org/10.1038/nprot.2006.339.

51. Di Veroli GY, Fornari C, Wang D, Mollard S, Bramhall JL, Richards FM, Jodrell DI. Combenefit: an interactive platform for the analysis and visualization of drug combinations. Bioinformatics. 2016; 32:2866-68. https://doi.org/10.1093/bioinformatics/btw230. 